\title{
$\mathrm{Ni}$ 基超合金の組織因子を用いたクリープ構成式の 温度一応力条件に対する適応性
}

\author{
伊津野仁史＼cjkstart横川忠晴＼cjkstart原田広史
}

物質・材料研究機構材料研究所超耐熱材料グループ

J. Japan Inst. Metals, Vol. 69, No. 8 (2005), pp. 735-738

(C) 2005 The Japan Institute of Metals

\section{Applicability of a Creep Constitutive Equation for Ni-Base Superalloys Using Structural Parameters at Different Temperature-Stress Conditions}

Hitoshi Izuno, Tadaharu Yokokawa and Hiroshi Harada

National Institute for Materials Science, Materials Engineering Laboratory, High Temperature Materials Group, Tsukuba 305-0005

A new creep constitutive equation for Ni-base superalloys with good reproducibility of high temperature-low stress condition $\left(1100^{\circ} \mathrm{C} / 137 \mathrm{MPa}\right)$ has been proposed. In this paper, an application of the creep constitutive equation for creep curves of lower temperature-high stress condition $\left(900^{\circ} \mathrm{C} / 392 \mathrm{MPa}\right)$ is discussed. Under the condition, it seems evidently that creep curves have no logarithmic elongation at early secondory creep stage, thus a parameter of the creep constitutive equation contained in the logarithmic part decreases to zero. Muti-regression analysis for each parameter of the creep constitutive equation with gammaprime composition, structural parameters as explanatory variables have been carried out in order to obtain a comparison of the result of multi-regression analysis of high-temperature low-stress condition. Predictions of creep curves at different temperature-stress conditions by interpolation is also discussed.

(Received April 22, 2005; Accepted July 11, 2005)

Keywords: nickel-base superalloy, creep curve prediction, creep constitutive equation, structural parameter, multi regression analysis

\section{1. 緒言}

$\gamma^{\prime}$ 析出強化型 $\mathrm{Ni}$ 基超合金(以下， $\mathrm{Ni}$ 基超合金と略)のすぐ れた高温クリープ強度は, 析出相である $\gamma^{\prime}$ 相が試験条件下 で異方的粗大化(ラフト化)することが主要因といわれてい る ${ }^{1,2)}$. このラフト化を反映して, $\mathrm{Ni}$ 基超合金は一次クリー プ域でのクリープ曲線が $\mathrm{S}$ 字状となる特異な形状を示す特 有のクリープ変形挙動を持つ. 従来知られているクリープ構 成式である $\theta$ 法3,4)， $\Omega$ 法5)などはこの部分をうまく表現でき なかった．このため, $\mathrm{Ni}$ 基超合金のクリープ変形挙動を精 密に記述する目的から, 一次クリープ域の特徵をよく再現で きる新しいクリープ構成式が必要である.

また，このクリープ変形挙動は異なる温度一応力条件での 異なるラフト化の過程を反映して変化する. $\mathrm{Ni}$ 基超合金の クリープ変形挙動を統一的に取り扱うためには, $\mathrm{Ni}$ 基超合 金のための新しいクリープ構成式はこの温度一応力変化をよ く反映できるものであることが望ましい.

我々はさきに, $\mathrm{Ni}$ 基単結晶超合金のクリープ曲線をよく 表現できるクリープ構成式を提案した ${ }^{6)}$.

$$
\varepsilon=I \times\left(A_{1}+S_{2}+S_{3}\right)
$$

ただし

$$
I=\exp \left(-\exp \left((t-\mu) / c_{1}\right)\right)
$$

および

$$
S_{i}=A_{i} \exp \left((t-\lambda) / c_{i}\right)(i=2,3)
$$

ここで $\varepsilon$ はクリープひずみ, $t$ は時間変数である. $A_{i}, c_{i}$ $(i=1,2,3), \mu, \lambda$ はパラメータであり, 以下にその説明を行 う.

$I$ は一次クリープの $\mathrm{S}$ 字状伸び， $A_{1}$ は一次クリープにお ける全伸び, $S_{2}$ と $S_{3}$ が二次抢よび三次クリープに対応して いる. 一次クリープ領域の形状決定にはパラメータ $A_{1}, c_{1}, \mu$ が，二次および三次クリープ領域に対してはそれぞれ $A_{2}, c_{2}$, $A_{3}, c_{3}$, 二次および三次クリープ両方に対して $\lambda$ が関与して いる. 式 $(2)$ は $\dot{y}=y \exp (-b t)$ という微分方程式を満たす もので, Gompertz 曲線と呼ばれる成長一飽和曲線の一種で ある。

我々は式 (1)を用いて, 非線形フィットにより NIMS 開 発の数種類の $\mathrm{Ni}$ 基超合金の $1100^{\circ} \mathrm{C} / 137 \mathrm{MPa}$ におけるク リープ曲線をよく再現できることを報告した6). また同合金 の $\gamma^{\prime}$ 組成および組織因子から式 (1)中の 8 つのパラメータ を重回帰分析し，材料組成抢よび組織因子からクリープ曲線 を直接予測することが可能であることを報告した7).

他方, 式 (1)の問題点として, 二次クリープ初期の近似 性の悪さがある. 数学的に検討すると式 (2) が飽和点に達 する $t=2 \mu$ 以降, 式 ( 1 )の微分值は最小を示し, その後ゆる やかな増加に転じる. 他方, 実際に観察されるクリープ速度 に颃いては, 最小クリープ速度はむしろクリープ伸びが指数 的増加に転じる直前であることが知られている。式 (1)の 
この特徵は最小クリープ速度を予測する際に問題を生じる. このため一次クリープから二次クリープ初期にかけての再現 性を高める目的で, 一次クリープ領域 $I$ に対数関数を乗じ, $S_{2}$ と $S_{3}$ を加算する改良を行った ${ }^{8)}$. 改良された一次クリー プ域および全体の式は以下の通りである.

$$
\begin{aligned}
& I^{\prime}=\exp \left(-\exp \left(-(t-\mu) / c_{1}\right)\right) \times \log (\beta t+e) \\
& \varepsilon=A_{1} \times I^{\prime}+\sum_{i=2,3} A_{i} \exp \left((t-\lambda) / c_{i}\right)
\end{aligned}
$$

$A_{i}, c_{i}, \mu, \lambda$ はそれぞれ式(2), (3) と同様の意味を持つパ ラメータ， $\beta$ が新たに加えられた項にふくまれるパラメー タ, また $e$ は指数関数の底である. $\beta$ が大きければ二次ク リープ領域前半でのクリープ速度が大きくなる. また $t=0$ の時点で $\log (\beta t+e)=1$ となることに注意されたい。この 式に対しても式 (1) と同様に非線形フィッティングおよび $\gamma^{\prime}$ 組成と組織因子による重回帰分析を行い, 高い再現性を得 ることができた。 また式 $(4)$ はクリープ速度の評価におい て式（1）に比べてよい推定を可能なものとしている.

我々は今回, 式 (1)，(4)のクリープ構成式を $900^{\circ} \mathrm{C} / 392$ $\mathrm{MPa}$ というより低温一高応力条件に抢ける $\mathrm{Ni}$ 基超合金のク リープ曲線に適応し，このクリープ構成式の適応性を拡張す ることを試みた。

\section{2. クリープ構成式の適応}

我々はまず NIMS 開発の $\mathrm{Ni}$ 基超合金約 20 種類の $900^{\circ} \mathrm{C} /$ $392 \mathrm{MPa}$ 条件下でのクリープ試験結果を式(1),(4)のそれ ぞれに対して非線形フィットを行い，再現性を比較した。こ の条件に括いては，対数部分を乗じない改良前の式 (1)の 方が再現性が高かった。これは低温-高応力条件でのクリー プ試験においては一次クリープ歪が高温-低応力の場合に比 べて大きくなく，そのために以前報告した ${ }^{8)}$ 二次クリープ初 期における対数的伸びが顕著でないことによるものと思われ る. この結果を踏まえ, 本研究で取り扱う構成式としては式 (1)を用いることとした。これは改良後の式 (4)に拈いて $\beta=0$ と拈いた，非対数的クリープ曲線であると説明でき る. 式 ( 1 ) は $t \geq 2 \mu$ であれば $I \approx 1$ であり, $I \times\left(A_{1}+S_{2}+\right.$ $\left.S_{3}\right) \approx A_{1}+S_{2}+S_{3}$ となって加法的に取り扱うことができる
ことに注意されたい。

以後, 高温一低応力の場合と同様に，構成式中の各パラ メータについて合金の $900^{\circ} \mathrm{C} に$ 打ける $\gamma^{\prime}$ 組成抢よび組織因 子を説明変数として重回帰分析を行い，外挿性を増す目的か ら变数増減法によって変数選択を行った．この重回帰結果を 用いて $900^{\circ} \mathrm{C} / 392 \mathrm{MPa}$ 条件に抢けるクリープ曲線の予測を 行った. ついで, 各パラメータの説明変数の係数を高温一低 応力に抢ける対応する係数と比較し，合金組成抢よび組織因 子がクリープ変形挙動に与える影響の温度一応力依存性につ いて考察を行った.

\section{3. 結 果}

Fig. 1 に例としてパラメータ $\lambda$ および $c_{1}$ のフィッティン グの值と計算值との比較を示す。横軸がフィッティングから 得られた值, 縦軸が重回帰式から求めた值である.すべての パラメータについて, 得られた重回帰式の重回帰係数は 0.9 以上であった. Fig. 2 はこの重回帰結果を用いた TMS75の $900^{\circ} \mathrm{C} / 392 \mathrm{MPa}$ に打けるクリープ曲線のパラメータ内挿に よって計算したクリープ近似曲線である.この合金は二次ク リープ初期において多少対数的クリープの傾向が見られたも のの，一次クリープ前期抢よび二次，三次クリープ全体にわ たってよい近似を得ることができた。

Fig. 3 に前回 ${ }^{7}$ 得られた $1100^{\circ} \mathrm{C} / 137 \mathrm{MPa}$ と今回の $900^{\circ} \mathrm{C} /$ $392 \mathrm{MPa}$ における非線形フィットで得られた $A_{1}$ の值の比較 を示す. $900^{\circ} \mathrm{C} / 392 \mathrm{MPa}$ 側では $A_{1}$ の值は明らかに小さく, いくつかの合金に拈いて $A_{1}$ が 0 となるものも見られた．こ の場合, クリープ変形挙動において一次クリープ伸びは明確 ではなく, クリープ曲線は単に $S_{2}$ と $S_{3}$ の和として表現され る. $\mathrm{Ni}$ 基超合金の特異な一次クリープ形状がラフト化と密 接な関連を持つものと考えると，このような合金においては 低温一高応力条件においてはラフト化が進行しないか，ある いはラフト化の進行がクリープ強度に寄与する以前に破断寿 命を迎えている可能性が示唆される。ただし， $A_{1}$ が 0 では なく非常に小さい值を持つ合金に関しては，一次クリープ域 に関与する他のパラメータである $c_{1}$ 抢よび $\mu$ が予想される 值の範囲から著しくかけ離れてはいなかった，つまり一次ク
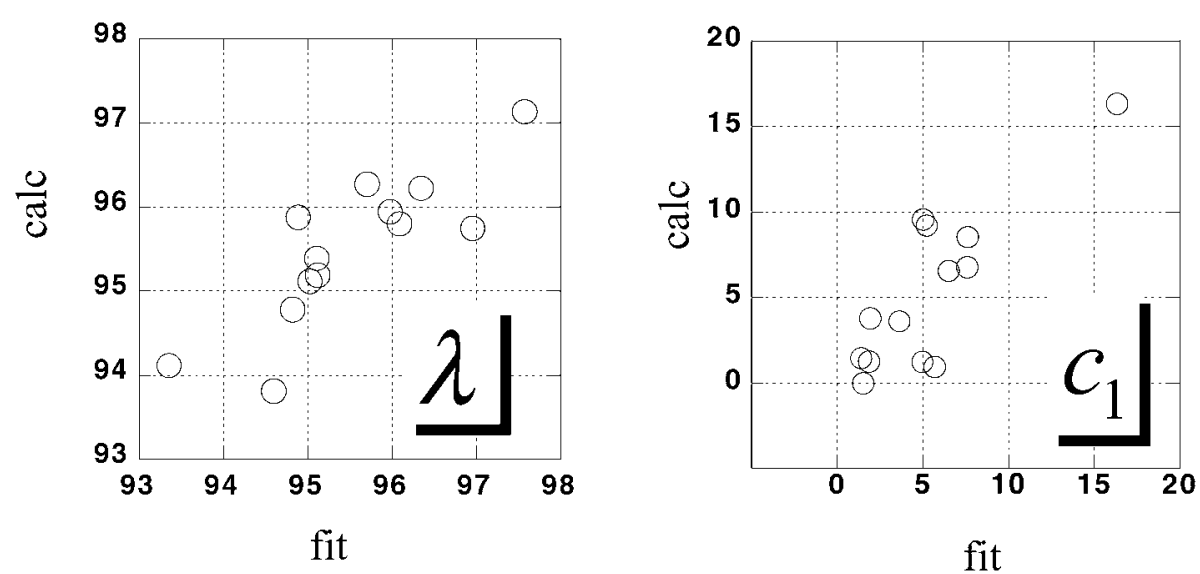

Fig. 1 Comparison of parameters of the creep constitutive equation. 
リープ伸びが非常に小さい場合でも， $\mathrm{Ni}$ 基超合金の特異な 一次クリープ形状はある程度保たれていると考えられる.こ の形状がラフト化の進行とどの程度関連しているかについて は, 一次クリープ中のラフト化の温度一応力依存性に関して の詳細な報告を待たなければならないと思われる。

Table 1 に本研究で求めた重回帰式中の説明变数である $\gamma^{\prime}$ 組成抢よび組織因子の係数を $1100^{\circ} \mathrm{C} / 137 \mathrm{MPa}$ における同 様の係数と比較した表を示す。イタリックで示した数值は $1100^{\circ} \mathrm{C} / 137 \mathrm{MPa}$ 条件下と $900^{\circ} \mathrm{C} / 392 \mathrm{MPa}$ 条件下で係数の 符号が逆転しているものである。係数の増減および符号の変 動をみることで, 温度一応力条件による添加元素および組織 因子のクリープ変形挙動への影響の変化を知ることができ る. 例えばMo は主に固溶強化および格子ミスフィット值の 負への増加を目的として添加されている，一次クリープ速度 に関係するパラメータ $c_{1}$ の Mo の係数は高温では負, 低温 側では正と逆転している． $c_{1}$ が大きくなれば一次クリープ速 度は低下するが，これは $900^{\circ} \mathrm{C} / 392 \mathrm{MPa}$ 側では $\mathrm{Mo}$ の固溶

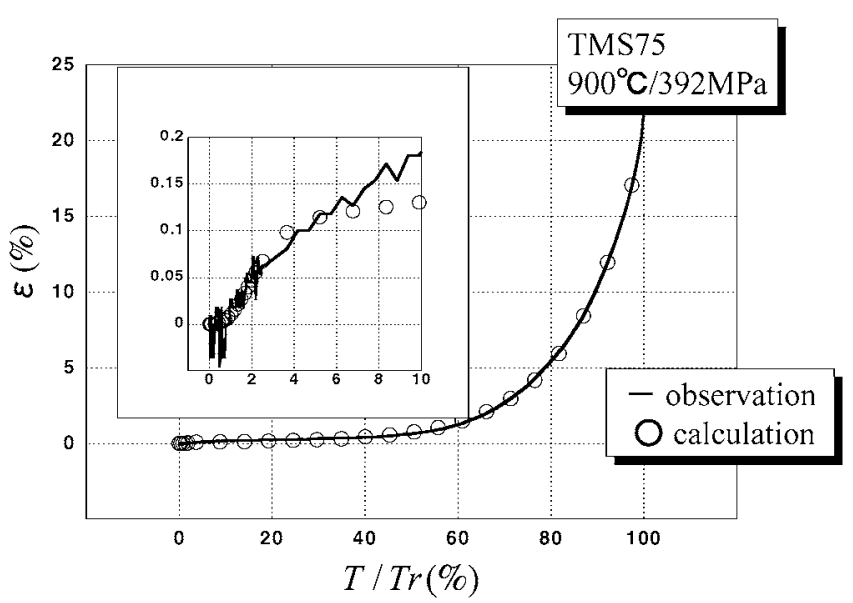

Fig. 2 Comparison of the creep curve of TMS-75 with calculated one.

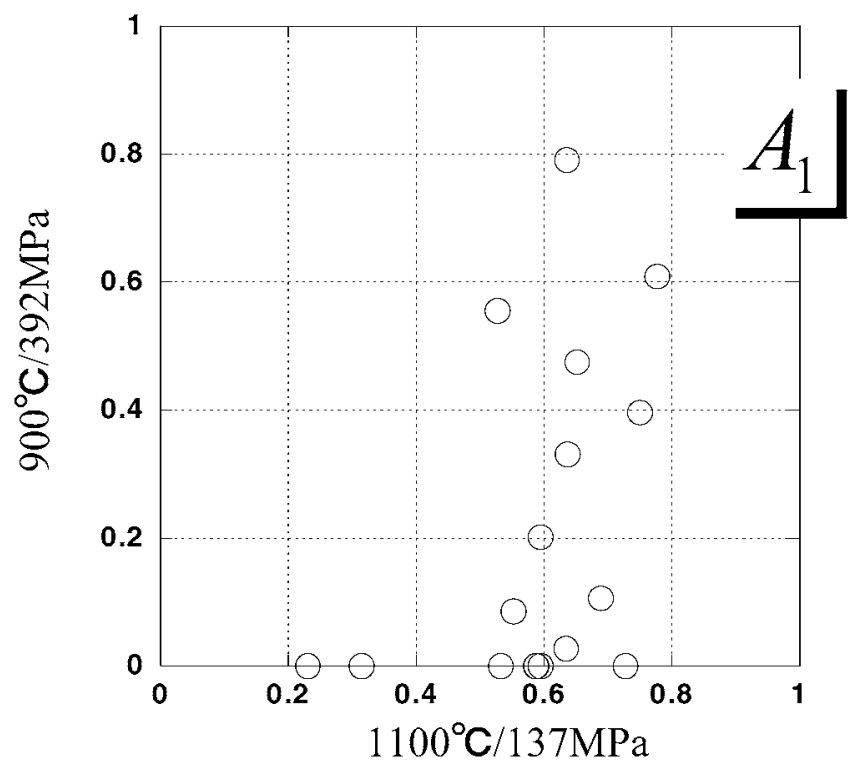

Fig. 3 Variance of $A_{1}$ between $1100^{\circ} \mathrm{C}$ and $900^{\circ} \mathrm{C}$.
強化が大きくはたらいたために一次クリープ速度が低下し, 一方, $1100^{\circ} \mathrm{C} / 137 \mathrm{MPa}$ 側での $\mathrm{Mo}$ のクリープ変形挙動への 影響はむしろ格子ミスフィットに着目して議論すべきである ことを示唆している.

また，一次クリープの継続時間に関係するパラメータ $\mu$ に着目すると，Wの $1100^{\circ} \mathrm{C} / 137 \mathrm{MPa}$ 条件下と $900^{\circ} \mathrm{C} / 392$ $\mathrm{MPa}$ 条件下での $\mu$ への影響が全く異なっている， $\mu$ が大き くなれば一次クリープの持続時間は長くなるが， $1100^{\circ} \mathrm{C} /$ $137 \mathrm{MPa}$ 条件下では $\mathrm{W}$ の係数が負, $900^{\circ} \mathrm{C} / 392 \mathrm{MPa}$ 条件 下では正である. $900^{\circ} \mathrm{C} / 392 \mathrm{MPa}$ においては W の拡散係数 の小ささが一次クリープの持続時間を長くしていることが示 唆される.さらに，最近注目されている第四世代 $\mathrm{Ni}$ 基超合 金の添加元素である $\mathrm{Ru}$ は組織安定性を目的に添加されたも のである ${ }^{9)} . \mathrm{Ru}$ に関するパラメータ $c_{1}, c_{2}, c_{3}, \lambda, \mu$ の係数の 符号は逆転し, かつ係数の変動に一定の傾向は見られない. $1100^{\circ} \mathrm{C} / 137 \mathrm{MPa}$ 条件下と $900^{\circ} \mathrm{C} / 392 \mathrm{MPa}$ 条件下のいずれ に拈いても, $\mathrm{Ru}$ のクリプ変形挙動への影響は明確ではな いと考えられる.

\section{4. 直接内挿によるクリープ曲線予測}

次に, 温度条件 $1000^{\circ} \mathrm{C}$ でのクリープ曲線予測を, 今研究 の結果を使用した直接内挿によって試みた。先の $1100^{\circ} \mathrm{C} /$ $137 \mathrm{MPa}, 900^{\circ} \mathrm{C} / 392 \mathrm{MPa}$ での各添加元素および組織因子の 係数の平均值を用いた重回帰式を作成し，TMS75 合金の $1000^{\circ} \mathrm{C}$ における $\gamma^{\prime}$ 組成および格子ミスフィット， $\gamma^{\prime}$ 相量に よって求められたパラメータによって計算したクリープ曲線 予測を Fig. 4 に示す。黒線で示した実測值は TMS75 の $1000^{\circ} \mathrm{C} / 245 \mathrm{MPa}$ に打けるクリープ曲線である。予測曲線は 本研究におけるクリープ構成式を使用して, 全く独自に得ら れたものであることに注意したい。

ただし今回の内挿結果は完全に温度のみに着目し, 応力条 件を無視して行ったものであり, 両者がともに考慮された内 挿の可能性については今後十分に検討する必要がある.

Table 1 The differences of coefficients between $900^{\circ} \mathrm{C}$ and $1100^{\circ} \mathrm{C}$.

\begin{tabular}{|c|c|c|c|c|c|c|c|c|c|}
\hline & & $A_{1}$ & $c_{1}$ & $\mu$ & $A_{2}$ & $c_{2}$ & $A_{3}$ & $c_{3}$ & $\lambda$ \\
\hline \multirow{2}{*}{$\operatorname{Re}$} & 1100 & -3.4 & -17.2 & -20.1 & 10.3 & 41.4 & -6.9 & -7.5 & - \\
\hline & 900 & 0.1 & - & - & - & 20.2 & 18.2 & -4.8 & 144.2 \\
\hline \multirow{2}{*}{ Mo } & 1100 & 7.8 & -2.3 & -7.1 & 11.9 & -2.2 & 3.1 & 2.3 & -1.10 \\
\hline & 900 & 2.7 & 10.0 & 2.2 & -12.9 & 8.5 & 8.6 & 14.2 & 34.0 \\
\hline \multirow{2}{*}{$\mathrm{Ta}$} & 1100 & -1.7 & - & -7.7 & - & 23.5 & -0.3 & 0.1 & - \\
\hline & 900 & 2.1 & - & -8.8 & -10.1 & - & 7.4 & 9.3 & 46.2 \\
\hline \multirow{2}{*}{ W } & 1100 & -0.5 & -4.1 & -7.1 & 3.1 & - & -0.5 & -0.7 & - \\
\hline & 900 & 1.3 & - & 5.1 & - & 16.5 & 13.3 & - & 105.0 \\
\hline \multirow{2}{*}{$\mathrm{Ru}$} & 1100 & 2.9 & 2.4 & 4.2 & - & -10.5 & 0.6 & -0.7 & -0.8 \\
\hline & 900 & 0.2 & -0.5 & -0.5 & - & 2.8 & 1.1 & 1.5 & 2.4 \\
\hline \multirow{2}{*}{$\mathrm{Vf}$} & 1100 & -11.1 & - & - & - & 85.7 & - & - & 5.9 \\
\hline & 900 & 9.7 & - & - & - & - & 0.5 & -7.0 & - \\
\hline
\end{tabular}




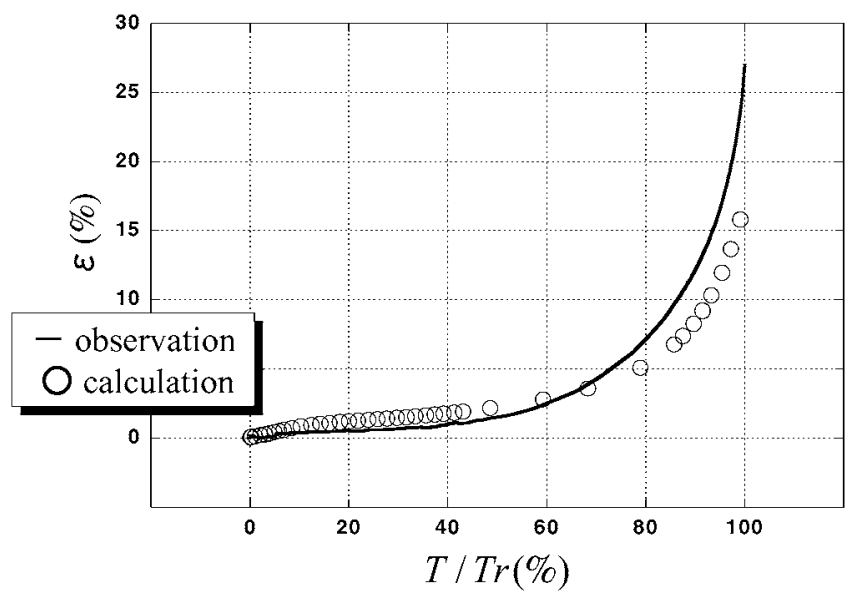

Fig. 4 A creep curve prediction by a simple interpolation.

\section{5. 結言}

$\mathrm{Ni}$ 基超合金の高温一低応力域でのクリープ特性をよく再現 することができる新しいクリープ構成式を低温一高応力側へ 適用し，よい適応結果が得られた． $\mathrm{Ni}$ 基超合金の温度一応力
の変化にともなう多様なクリープ変形挙動を統一的に記述し 議論する上で本構成式は有用であるとの結論を得た。 また， 単なるクリープ变形挙動の説明にとどまらず，材料組成から 直接クリープ曲線を予測することを可能にするものでもある.

\section{文} 献

1) J. X. Zhang, T. Murakumo, Y. Koizumi, T. Kobayashi, H. Harada and S. Masaki Jr.: Metal. Mater. Trans. 33A(2002) 3741-3746.

2) T. Ichitsubo, D. Koumoto, M. Hirao, K, Tanaka, M. Osawa, T. Yokokawa and H. Harada: Acta Mater. 52 (2003) 4033-4044.

3) R. W. Evans, J. D. Parker and B. Wilshire: Recent Advances in Creep and Fracture of Engineering Materials and Structures, (Pineridge Press, Swansea, 1969) p. 135.

4) R. W. Evans, I. Beden and B. Wilshire: Creep and Fracture of Engineering Materials and Structures, (Pineridge Press, Swansea, 1984) p. 1277.

5) M. Prager: ASME-PVP 288(1994) 401.

6) H. Izuno, T. Yokokawa, M. Osawa, S. Odaka and H. Harada: Collected Abstracts of the 2003 Autumn Meeting of the Japan Inst. Metals (2003) p. 443.

7) H. Izuno, T. Yokokawa, M. Osawa, S. Odaka and H. Harada: J. Japan Inst. Metals 68(2004) 526-529.

8) H. Izuno, T. Yokokawa and H. Harada: J. Japan Inst. Metals 69 (2005) 229-232.

9) Y. Koizumi, H. Koguchi, T. Yokokawa, T. Kobayashi, M. Osawa, T. Kimura and H. Harada: J. Japan Inst. Metals 68 (2004) 54-57. 